\title{
- Percepção morfológica de animais aquáticos pela comunidade pesqueira de Acupe, Santo Amaro, Bahia: uma abordagem etnozoológica
}

\author{
Francisco José Bezerra Souto ${ }^{1 *} \&$ Rodrigo Stolze Pacheco ${ }^{2}$
}

${ }^{1}$ Laboratório de Etnobiologia e Etnoecologia, Departamento de Ciências Biológicas, Universidade Estadual de Feira de Santana, Avenida Transnordestina, s.n., Novo Horizonte, 44036-900, Feira de Santana, Bahia, Brasil.

${ }^{2}$ Secretaria de Meio Ambiente do Estado da Bahia, Rua Viviane Vieira Pedreira, 19, Ipitanga, 42700-000, Lauro de Freitas, Bahia, Brasil.

\begin{abstract}
Resumo - A etnozoologia vem sendo utilizada com sucesso no estudo das interações entre zoologia e cultura. Neste corpo de conhecimentos, é comum a utilização de uma terminologia própria para denominar diferentes partes do corpo dos animais, o que é conhecido como topografia corporal. O presente trabalho tem como objetivo conhecer as terminologias utilizadas por pescadores de Acupe (Santo Amaro - Bahia) para alguns animais capturados localmente, analisando-as sob o prisma de uma cognição comparada com a literatura zoológica. A topografia corporal foi estudada por meio da apresentação de fichas $(\mathrm{N}=100)$ a 68 pescadores, contendo desenhos de siris, camarões, caranguejos e peixes retirados da literatura científica. Nas nomeações registradas, foram identificados três padrões: polionomia, funcionalidade atribuída e codificação de analogia antropomórfica. Em pelo menos um caso (pesca do caranguejo), este conhecimento traduziu-se em uma prática com implicação etnoconservacionista. Os resultados demonstraram que pescadores locais dispõem de uma vasta terminologia para nomear estruturas e regiões corporais e suas funções, sendo algumas delas compatíveis com a literatura zoológica.

Palavras-chave adicionais: conhecimento tradicional, etnozoologia, morfologia, topografia corporal.
\end{abstract}

\begin{abstract}
Morphological perception of aquatic animals by the Acupe fishing community, Santo Amaro, Bahia: an ethnozoological approach) - Ethnozoology has been used successfully in studies of the interaction between zoology and culture. In that body of knowledge, it is common to use a personal terminology to name different animal body parts; this is known as body topography. The aim of this work is to understand the terms used by the Acupe fishermen (Santo Amaro - Bahia, Brazil) for some of the locally caught animals, analysing them from the perspective of folk knowledge compared with the zoological literature. The body topography was studied by presenting picture-cards $(\mathrm{N}=100)$, showing images of swimming crabs, shrimps, crabs and fish taken from the scientific literature, to 68 fishermen. The folk terminology recorded was divided into three categories: polynomia, suggested function, and anthropomorphic analogy. In at least one case (crab-catching), this knowledge translates into a method with ethnoconservation implications. The results showed that the local fishermen have an extensive terminology to name structures and body parts and their functions, and in some cases this knowledge was comparable to that in the zoological literature.
\end{abstract}

Aditional key words: body topography, ethnozoology, folk knowledge, morphology.

Na base da interação entre comunidades tradicionais e ambiente está um vasto arcabouço cultural que inclui cosmologias, ideologias, crenças, além de um vasto corpo de conhecimentos que, segundo Chassot (1994), não estão nos livros e que o meio acadêmico desconhece, uma vez que são transmitidos oralmente de geração a geração, fruto de experiências diretas e de contato com o meio ambiente por vários povos indígenas e locais através dos séculos.

A etnoecologia vem demonstrando ser uma excelente ferramenta teórico-metodológica para o estudo das interações entre ecologia e cultura (Souto 2008). Toledo (1992), que inclui a etnozoologia como um dos componentes da Etnoecologia, sugere esta como um método cientificamente aceitável para a avaliação das formas de apropriação e percepção da natureza. A etnoecologia é

*Autor para correspondência: franze.uefs@gmail.com

Editor responsável: Marcelo Alves Ramos

Recebido: 16 maio 2011; aceito: 11 Ago. 2011. definida por Marques (2001) como o estudo transdisciplinar dos pensamentos (conhecimentos e crenças), dos sentimentos e dos comportamentos que intermediam as interações entre as populações humanas e os demais elementos dos ecossistemas dos quais elas dependem, bem como dos impactos ambientais daí decorrentes.

No estado da Bahia, as tradições de pesca são significativas porque contêm um conhecimento ambiental refinado, acumulado em centenas de anos (Cordell 2001). Neste conhecimento, é comum a utilização de uma terminologia própria para denominar diferentes partes do corpo dos animais (Posey 1987; Marques 1995; Costa Neto 1998), o que Silva (1988) chamou de topografia corporal. O presente trabalho tem como objetivo conhecer as terminologias utilizadas por pescadores de Acupe (Santo Amaro - Bahia) para alguns animais capturados localmente, analisando-as sob o prisma de uma cognição comparada com a literatura zoológica.

Sitientibus série Ciências Biológicas 11(2): 103-111. 2011. 


\section{MÉTODOS}

Os trabalhos de campo foram realizados no período de abril a dezembro de 2002, com 68 pescadores do distrito de Acupe (Santo Amaro - Bahia), que está localizada na face oeste da Baía de Todos os Santos (12³9'39'S, 38 44'34”'W; Figura 1). As entrevistas sempre foram precedidas pela identificação do entrevistador, por uma rápida explanação sobre o trabalho e uma solicitação para que dele participassem. A topografia corporal de siris, camarões, caranguejos e peixes foi estudada por meio da apresentação de fichas $(\mathrm{N}=100)$ com desenhos retirados da literatura científica, quando se perguntava sobre os nomes e as funções de estruturas e regiões corporais. Em algumas ocasiões, mais de um desenho foi submetido a um mesmo pescador, tendo em vista a versatilidade da pesca, local, em que pescadores são especialistas em várias artes de pesca e por isso detêm conhecimento sobre vários recursos. Durante as entrevistas, procurou-se utilizar termos do linguajar nativo, a fim de facilitar a comunicação. A amostra dos informantes foi definida a partir de indivíduos oportunisticamente encontrados em seus espaços de pesca ou residências, e pelo critério de "especialistas nativos(as)", que são aquelas pessoas autorreconhecidas e reconhecidas pela própria comunidade como culturalmente competentes (Marques 1995). Optou-se por uma análise eticista-emicista, na qual as informações êmicas (tradicionais) foram confrontadas com as éticas (acadêmica) (Feleppa 1986). As fichas se encontram nas dependências do Laboratório de

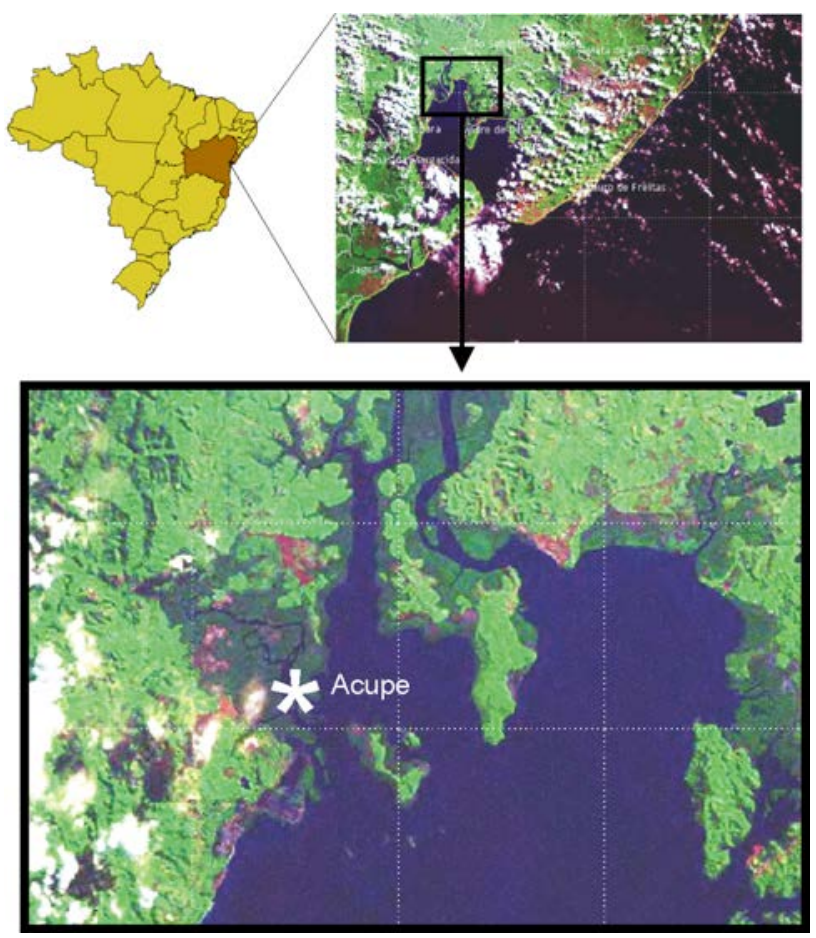

Figura 1. Localização da área de trabalho: distrito de Acupe município de Santo Amaro, estado da Bahia (Modificado do C.E.I. 1994).
Etnobiologia e Etnoecologia da Universidade Estadual de Feira de Santana.

\section{Resultados e Discussão}

Em Acupe, a adoção de termos para nomear determinadas estruturas ou regiões corporais de mariscos e peixes se mostrou uma prática bastante comum (Figuras 2-5). Mourão (2000), em um estudo etnoictiológico com pescadores de um estuário na Paraíba, registrou vários nomes vernaculares para estruturas corporais de peixes, tais como "zoio" (olho), "umbigo" (estômago pilórico dos Mugilidae), "beiço"(maxila e mandíbula), "bico” (focinho), "catocos" (cláspers nos Condrichthyes) e "pedras na boca" (placas dentárias). Magalhães (2008), Casal (2010) e Martins et al. (2011), trabalhando em diferentes regiões do litoral baiano também registraram conhecimentos similares entre pescadores. A percepção nativa de diversas partes ou regiões corporais e seus respectivos nomes, formas e as cores do corpo têm função de identificar as diferentes variedades de animais: "a linha (lateral) diz a qualidade do peixe, diferencia as marca... cada qual tem sua listra." ou "o siri azul é o siri-de-coroa." Desta forma, constata-se que a topografia corporal pode ter uma importância significativa para estudos de etnotaxonomia, tendo em vista que a morfologia externa é o principal critério na diferenciação das variedades.

Determinadas estruturas ou regiões do corpo também
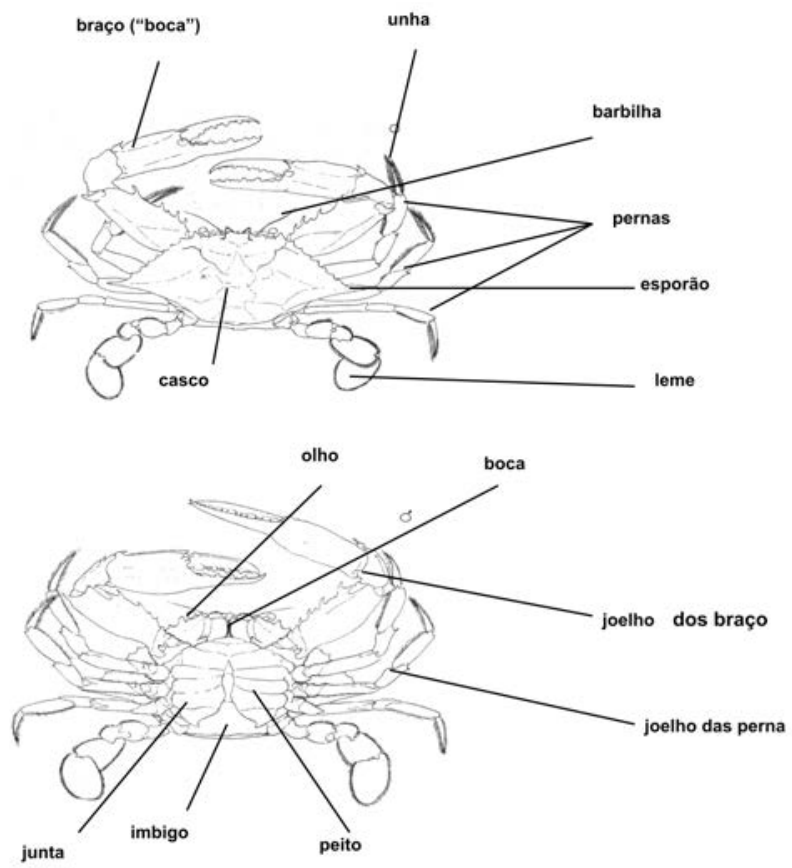

Figura 2. Topografia corporal de um siri; codificação dos pescadores de Acupe (adaptada de Narchi 1973) 


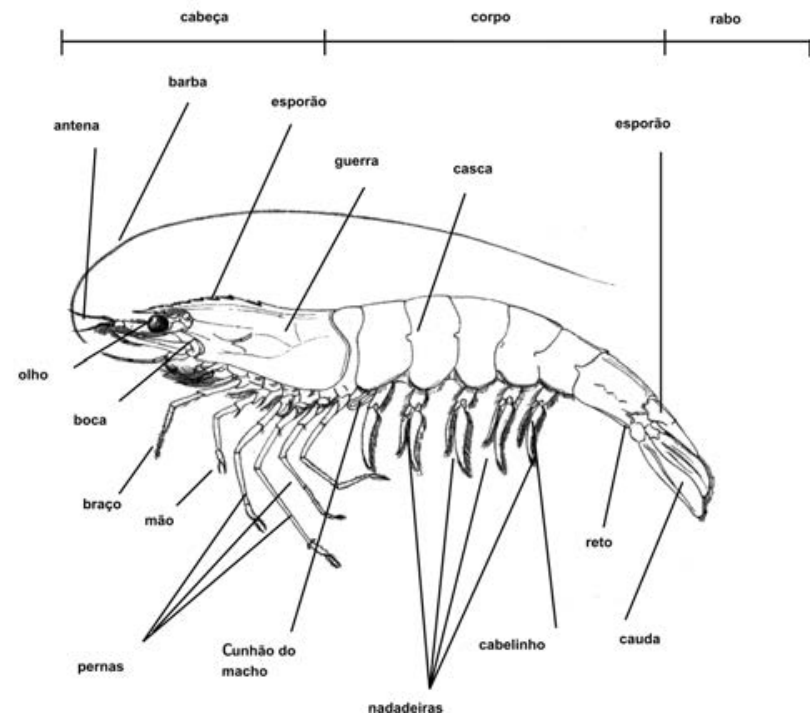

Figura 3. Topografia corporal de um camarão; codificação dos pescadores de Acupe (adaptada de Narchi 1973).

são utilizadas por pescadores de Acupe para se fazer a distinção entre os sexos de alguns animais. Os siris e caranguejos são os que têm os sexos mais facilmente diferenciados, sendo usados para isto a forma do abdome, chamado por eles de "imbigo" ou "tampo", o tamanho e a forma do corpo, bem como a presença de gonópodos e gonóporos, como observa-se nos trechos abaixo:

"O macho tem o umbigozinho estreito e comprido e as fêmea têm o umbigozinho mais largo e redondo."

"Os machos são maiores e são mais compridos e as fêmeas são menores e mais arredondadas."

Para os caranguejos, o dimorfismo também é percebido pela quantidade de "pêlos" ou "cabelos" nas patas. Estas características também são indicadas por Pinheiro \& Fiscareli (2001) para a distinção de macho e fêmeas de caranguejos. A identificação de machos e fêmeas de caranguejos no mangue também é feita pelo rastro deixado por eles na entrada da toca e, por alguns poucos pescadores, pela forma das fezes.

"Na perna dele tem sempre mais cabelo do que na dela. A carangueja quase num tem cabelo. As perna dela é quase lisa."

"A fêmea pisa na ponta da unha e o macho arreia a unha toda na lama. Fica saliente. Então, ele largou o peso dele todo ali. A unha dele fica toda deitada ali. Então, nós vê aquele lapo, aí esse é o macho. E a fêmea não, vai na pontinha. Fica tudo calanhado na boca do buraco."
"O cocô do macho é comprido e o cocô da fêmea é curtinho. Só eu ver o buraco eu conheço logo!"

Nordi (1992) e Maneschy (1993) também registraram em comunidades de caranguejeiros a identificação do sexo dos animais pelo rastro deixado na lama. Alves (2002), testando esse conhecimento, chegou a uma percentagem de $74 \%$ de acerto nesta diferenciação entre catadores da Paraíba. Botelho et al. (2000) também verificaram entre pescadores nordestinos a capacidade de distinguir machos e fêmeas pela forma das fezes e dos rastros deixados pelos indivíduos. A identificação dos sexos dos caranguejos em Acupe adquire uma importância produtiva e etnoconservacionista, pois possibilita aos pescadores realizarem uma coleta seletiva. Nesta situação, a coleta de machos gera mais renda, já que, por serem maiores, atingem maior valor de mercado; e fêmeas podem ser poupadas, ampliando as chances de reposição dos estoques.

Segundo Brusca \& Brusca (2007), a maioria dos machos dos Malacostraca possui apêndices torácicos modificados (gonópodos) para a tranferência de espermatóforos durante a cópula. Esta estrutura nos camarões foi identificada e chamada de "pênis" ou "cunhão" por alguns pescadores de Acupe. Para os camarões, a distinção do sexo também foi feita por alguns poucos pescadores pelo tamanho do indivíduo: "A camaroa é maior do que o camarão."

A distinção dos sexos nos peixes se mostrou menos comum, o que provavelmente se deve ao fato de não haver dimorfismo sexual externo na maior parte das espécies de teleósteos (Pough et al. 1993). Ainda assim, alguns pescadores utilizam caracteres morfológicos externos para diferenciar os machos das fêmeas de alguns peixes: " $O$ corongo, que é branco, a gente já sabemos quem é o macho e quem é a fêmea. A corongo têm o rabo redondo e o corongo macho tem o rabo todo fino." Para o miroró (Gobionellus sp.), foi afirmado que os machos são mais "esguios", enquanto as fêmeas são "curtas" e "mais "largas".

Para camarões e peixes, foi registrada uma divisão do corpo em três regiões distintas e delimitadas: a "cabeça", o "corpo" e o "rabo". Nos camarões, a "cabeça" vai do início do rostro (esporão) ao final do cefalotórax; o "corpo" vai do primeiro ao penúltimo segmento abdominal (pleossoma); e o "rabo" corresponde ao leque caudal (telson e urópodos). Nos peixes, a "cabeça" se inicia na boca e vai até o final do opérculo ("queixal"); o "corpo" vai do final deste ponto até o pendúnculo caudal; e o "rabo" corresponde à nadadeira caudal.

Pelo menos três padrões gerais foram identificados na topografia corporal entre os pescadores de Acupe: a polionomia, que é a aplicação de mais de um nome à mesma estrutura; a funcionalidade atribuída, que se refere à atribuição de funções às estruturas; e a codificação de analogia antropomórfica, que demonstra a forte influência de termos da morfologia humana na nomeação das partes 
dos animais.

A polionomia foi encontrada para várias estruturas corporais e para todos os animais analisados neste trabalho. Nos siris, por exemplo, as antenas receberam nomes como "cabelo dos olhos", "barbilha", "antenas", "barbazinha", "sobrancelha" e "pestana". Para os camarões, foram encontrados os termos "pernas", "perninhas", "barbatanas" e "nadadeiras" como denominações para os pleópodos. A semelhança corporal entre siris e caranguejos certamente foi responsável pelo fato de algumas partes corporais receberem o mesmo nome, tais como "peito" e "barriga", sinônimos para a porção ventral do cefalotórax. Os peixes foram os que mostraram maior uniformidade de nomes aplicados às estruturas, embora haja exemplos de polionomia, como a linha lateral, que é chamada de "linha" ou "listra". Esta uniformidade provavelmente está relacionada ao tamanho do animal, cujas estruturas são mais perfeitamente visíveis.

Um caso inverso da polionomia foi registrado para os peixes, ou seja, quando estruturas diferentes receberam o mesmo nome (e.g., nadadeiras dorsais, anal, peitorais e pélvicas foram nomeadas de "abas"). Os nomes das estruturas que aparecem nos Apêndices 1-3 foram os mais utilizados pelos pescadores entrevistados. Casal (2010) registrou também os mesmos padrões, mas a polionomia apareceu com a maioria das estruturas corporais apresentando uniformidade de nomes.

Além de nomear, pescadores de Acupe também atribuem funções às várias estruturas que compõem o corpo de crustáceos e peixes (Apêndice 4). As atribuições feitas com mais segurança e frequência foram para funções mais comuns ou visíveis, como locomoção, captura de alimento e proteção. Os pereiópodos nos siris recebem nomes de



Figura 4. Topografia corporal de um caranguejo (dorsal acima; ventral abaixo): codificação dos pescadores de Acupe (adaptada de Pinheiro \& Fiscareli 2001).

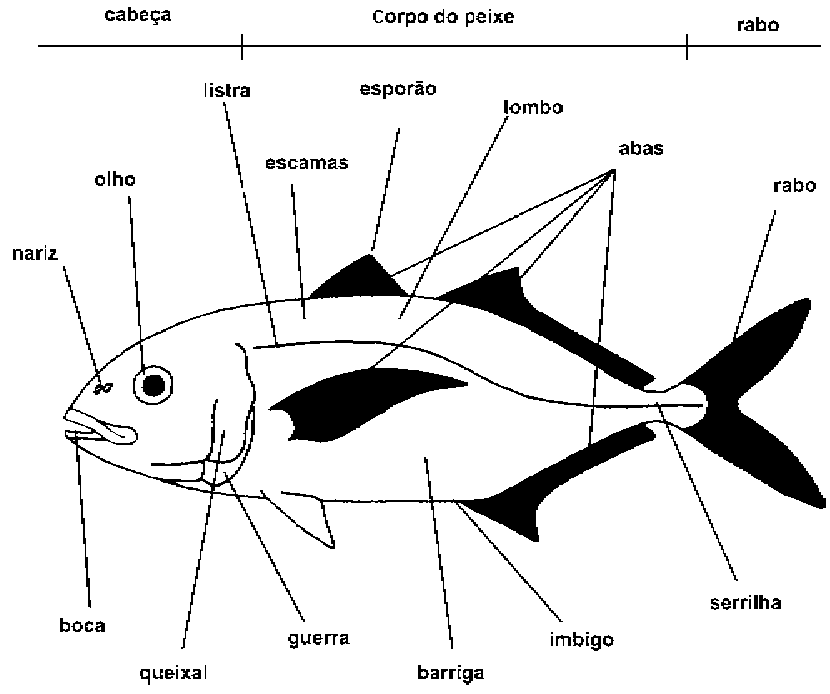

Figura 5. Topografia corporal de um peixe. Codificação dos pescadores de Acupe (adaptada de Szpilman 2000).

acordo com a função que exercem: o primeiro par (quelípodo) é chamado de "braço" ou, mais comumente, de "boca", que tem função de "pegar o alimento". O termo boca parece ser herança histórica dos portugueses, uma vez que já era usado por Gabriel Soares de Sousa, em 1587 (Sousa 2000), para designar tais estruturas: "Estes caranguejos têm as pernas grandes e duas bocas ainda maiores com que mordem muito." Os pescadores entrevistados, porém, sempre fizeram questão de dizer que aquela não é a "boca verdadeira". Do segundo ao quarto par, recebem o nome de "pernas", cuja função atribuída é a locomoção (andar). Diferenças de nomes e de vocabulário à parte, as funções atribuídas a estas estruturas são semelhantes àquelas encontradas na literatura científica (e.g., Barnes 1984; Ruppert et al. 2005; Brusca \& Brusca 2007). Nos caranguejos, com exceção do quinto par de pereópodos ("caranguejo não tem leme") e da "boca" que também é utilizada para "cavar o buraco", as mesmas funções foram atribuídas. O Ucides cordatus (Linnaeus, 1763) comumente tem um dos quelípodos mais desenvolvidos que o outro, mas, quando isso não ocorre, são chamados em Acupe de "boca igual". Entre os pescadores da região do Salgado (Pará), estes caranguejos recebem o nome de "manicujás" (Andrade 1983).

Nos camarões, a função de defesa foi bastante enfatizada pelos entrevistados, que apontaram a "quilha" ou "serrilha" (rostro) e o "esporão" ou "espinho" (telso) como as estruturas responsáveis. Esta maior ênfase foi dada, certamente, por serem os pescadores frequentes vítimas de ferimentos nas mãos, durante a retirada dos animais da rede: "o camarão malha mais pela cabeça... fica preso pela serrilha." As denominações dadas ao rostro tornam-se particularmente interessantes diante da afirmação de Barnes (1984), de que o cefalotórax geralmente é portador de um rostro serrilhado em forma de quilha. Nos peixes, a defesa é atribuída ao raio mais duro das nadadeiras dorsais, que 
recebe também o nome de "esporão".

As nadadeiras dos peixes foram as estruturas que mais frequentemente tiveram funções atribuídas pelos pescadores. Estas funções, entretanto, algumas vezes foram generalizadas para todas as nadadeiras, o que não coincide com a literatura zoológica, pois cada uma delas tem funções específicas (Orr 1986). Outra situação de não correspondência entre os conhecimentos tradicional e acadêmico foi a atribuição de uma função respiratória à bexiga natatória ("bucho"), uma vez que esta estrutura está relacionada à flutuabilidade e o gás nela contido é o nitrogênio (Carvalho-Filho 1992; Szpilman 2000).

Ainda que a funcionalidade de estruturas corporais identificadas pelos entrevistados tenha sido mais comumente feita àquelas funções mais simples (e.g., comer, nadar, andar, etc.), um conhecimento nativo também foi registrado para funções mais elaboradas, tais como localização e orientação espacial e reconhecimento alimentar, atribuídas às antenas. Esta informação coincide com aquelas da literatura zoológica, pois na maioria dos crustáceos existe uma variedade de quimiorreceptores e mecanorreceptores nas antenas (Brusca \& Brusca 2007). A "guerra" ou "garguelo" (brânquias associadas aos rastros branquiais) dos peixes foram associadas corretamente à respiração ("eles respira por ela") e a obtenção do alimento ("penera o alimento"), conforme o que se encontra na literatura acadêmica (Young 1981; Orr 1986; Carvalho-Filho 1992; Pough et al. 1993; Szpilman 2000).

Segundo McFarland (1981), existe uma tendência geral em atribuir características humanas aos animais, entre as quais estão as morfológicas, ao que Silva (1988) se refere como um revestimento antropocêntrico que se observa subjacente ao exercício de organização do mundo. Posey
(1987) registrou entre os Kayapó que algumas estruturas morfológicas das abelhas recebem nomes análogos ao do corpo humano. Entre os pescadores de Acupe, a codificação de analogia antropomórfica se mostrou de forma bem pronunciada, tendo em vista o registro de nomes como "sobrancelha", “joelho", "pernas", "unha”, "mão", "braço”, "nariz", "pênis", "cabelo", "imbigo”, "barriga”, entre outros. Diferentemente, Montenegro (2002) encontrou entre pescadores do Baixo São Francisco alagoano, a prevalência da aplicação de termos ictiológicos à morfologia dos camarões. Em Acupe, de uma forma geral, a nomeação de estruturas contém elementos encontrados por ambos os autores.

\section{Considerações Finais}

Os dados encontrados neste trabalho revelam que pescadores de Acupe detêm uma terminologia própria para nomear estruturas ou regiões corporais de animais aquáticos. Esta nomeação obedece critérios e/ou padrões e serve para auxiliar, inclusive, na diferenciação das variedades dos organismos, o que torna estudos de topografia corporal importantes ao conhecimento etnotaxonômico.

\section{Agradecimentos}

À comunidade pesqueira de Acupe, que com gentileza e boa vontade aceitou participar deste trabalho, e ao prof. Dr. José Geraldo Wanderley Marques, pela amizade e orientação neste trabalho.

\section{REFERÊNCIAS}

Alves, R.R.N. 2002. Estrutura Populacional de Ucides cordatus (L., 1763) (Decapoda, Brachiura) e a Atividade de Coleta no Manguezal do Estuário do Rio Mamanguape, Paraíba: um enfoque social e etnoecológico. Dissertação de Mestrado. Universidade Federal da Paraíba.

Andrade, J. 1983. Folclore na Região do Salgado, Pará. Teredos na alimentação: profissões ribeirinhas. 2 ed. Escola de Folclore, São Paulo.

Barnes, R.D. 1984. Zoologia dos Invertebrados. Livraria Rocca, São Paulo.

Botelho, E.R.; Santos, M.C.F. \& Pontes, A.C.P. 2000. Algumas considerações sobre o uso da redinha na captura do caranguejouçá, Ucides cordatus (Linnaeus, 1763) no litoral sul de Pernambuco, Brasil. Boletin Técnico Científico do Centro de Pesquisa e Gestão de Recursos Pesqueiros do Litoral Nordeste 8(1): 55-71.

Brusca, R.C. \& Brusca, G.J. 2007. Invertebrados. 2 ed. Guanabara Koogan, Rio de Janeiro.

C.E.I. (Centro de Estatística e Informações) 1994. Informações Básicas dos Municípios Baianos: Recôncavo Sul. Governo do Estado da Bahia, Salvador.

Carvalho-Filho, A. 1992. Peixes da Costa Brasileira. 3 ed. Melro, São Paulo.

Casal. F. 2010. Maré, Mangue e Marisco: etnoecologia da pesca artesanal de crustáceos na comunidade do Angolá (RESEX Marinha Baía do Iguape), Maragogipe-BA. Dissertação de Mestrado. Universidade Estadual de Feira de Santana.

Chassot, A. 1994. A Ciência através dos Tempos. Ed. Moderna, São Paulo.

Cordell, J. 2001. Marginalidade social e apropriação territorial marítima na Bahia. In: A.C. Diegues \& A.C. Moreira (orgs), Espaços e Recursos Naturais de Uso Comum. NUPAUBUSP, São Paulo, p. 139-160.

Costa Neto, E.M. 1998. Etnoictiologia, Desenvolvimento e Sustentabilidade no Litoral Norte Baiano. Um estudo de caso entre pescadores do Município de Conde. Dissertação de Mestrado, Universidade Federal de Alagoas.

Feleppa, R. 1986. Emics, etics, and social objetivity. Current Anthropology 27(3): 243-254.

Maneschy, M.C. 1993. Pescadores nos manguezais: estratégias 
técnicas e relações sociais de produção na captura de caranguejo. In: L. Furtado, W. Leitão \& F.M. Melo (orgs), Povos das Águas: realidade e perspectivas na Amazônia. Museu Paraense Emílio Goeldi, Belém do Pará, p. 19-62.

McFarland, D. 1981. The Oxford Companion to Animal Behaviour. Oxford University Press, Oxford.

Magalhães, H.F. 2008. Etnoecologia de Caranguejos (Decapoda: Brachyura) no Litoral Norte do Estado da Bahia: um estudo de caso com pescadores artesanais do Município de Conde. Dissertação de Mestrado. Universidade Estadual de Santa Cruz.

Marques, J.G.W. 1995. Pescando Pescadores: etnoecologia abrangente no Baixo São Francisco. NUPAUB-USP, São Paulo.

Marques, J.G.W. 2001. Pescando Pescadores: ciência e etnociência em uma perspectiva ecológica. 2 ed. NUPAUB/ Fundação Ford, São Paulo.

Martins, V.S.; Schiavetti, A. \& Souto, F.J.B. 2011. Ethnoecological knowledge of the artisan fishermen of octopi (Octopus spp.) in the community of Coroa Vermelha (Santa Cruz Cabrália, Bahia). Anais da Academia Brasileira de Ciências 83(2): 513-522.

Miller, S.A. \& Harley, J.P. 1996. Zoology. WCB/McGraw-Hill, Boston.

Montenegro, S.C.S. 2002. A Conexão Homem/Camarão (Macrobrachium carcinus, M. acanthurus) no Baixo São Francisco Alagoano: uma abordagem etnoecológica. Tese de Doutorado. Universidade Federal de São Carlos.

Mourão, J.S. 2000. Classificação e Ecologia de Peixes Estuarinos por Pescadores do Estuário do Rio Mamanguape - PB. Tese de Doutorado. Universidade Federal de São Carlos.
Narchi, W. 1973. Crustáceos: estudos práticos. Polígono/EDUSP, São Paulo.

Nordi, N. 1992. Os Catadores de Caranguejo-Uçá (Ucides cordatus) da Região da Várzea Nova (PB): uma abordagem ecológica e social. Tese de Doutorado. Universidade Federal de São Carlos.

Orr, R.T. 1986. Biologia dos Vertebrados. 5 ed. Livraria Rocca, São Paulo.

Pinheiro, M.M.A. \& Fiscarelli, A.G. 2001. Manual de Apoio à Fiscalização do Caranguejo-Uçá (Ucides cordatus). CEPSUL/IBAMA, Itajaí.

Posey, D. 1987. Etnoentomologia de tribos indígenas da Amazônia. In: D. Ribeiro (ed.), Suma Etnológica Brasileira. Vol. 1 (Etnobiologia). Ed. Vozes, Petrópolis, p. 251-271.

Pough, F.H.; Heiser, J.B. \& McFarland, W.N. 1993. A Vida dos Vertebrados. Atheneu, São Paulo.

Ruppert, E.E.; Fox, R.S. \& Barnes, R.D. 2005. Zoologia dos Invertebrados. 7. ed. Rocca, São Paulo.

Silva, G. 1988. Tudo que Tem na Terra Tem no Mar. Dissertação de Mestrado. Universidade Federal do Rio de Janeiro.

Sousa, G.S. 2000. Tratado Descritivo do Brasil em 1587. 9 ed. rev. atual. FJN, ed. Massagana, Recife.

Souto, F.J.B. 2008. A Ciência que Veio da Lama. Etnoecologia em áreas de manguezal. Série Estudos e Debates. NUPEEA/ SBEE, Recife.

Szpilman, M. 2000. Peixes Marinhos do Brasil: guia prático de identificação. Mauad, Rio de Janeiro.

Toledo, V.M. 1992. What is ethnoecology? Origins, scope and implications of rising discipline. Etnoecologia 1(1): 5-27.

Young, J.Z. 1981. The Life of Vertebrates. 3 ed. Claredon Press, Oxford. 
Apêndice 1. Comparação entre o conhecimento nativo (Acupe, Santo Amaro, Bahia) e o conhecimento acadêmico relativo a codificação da topografia corporal dos peixes.

\begin{tabular}{|c|c|c|c|}
\hline Nome(s) vernacular(es) & $\begin{array}{l}\text { Nome na } \\
\text { literatura }\end{array}$ & Função atribuída pelos nativos & $\begin{array}{l}\text { Função atribuída na } \\
\text { literatura* }\end{array}$ \\
\hline Cabeça & Cabeça & - & - \\
\hline Olho & Olho & “Visão” & Visão \\
\hline Nariz & Fendas nasais & $\begin{array}{l}\text { "Faro, sentir o paladaro } \\
\text { alimento" }\end{array}$ & Olfato, paladar \\
\hline Boca & Boca & "Comer" & - \\
\hline Queixal; queixada & Opérculo & "Se alimentar; beber água" & $\begin{array}{l}\text { Proteção da cavidade } \\
\text { branquial }\end{array}$ \\
\hline Guerra; ga rguelo & Brânquias & $\begin{array}{l}\text { "Respira por ela; penerao } \\
\text { alimento; retira a impureza da } \\
\text { água" }\end{array}$ & $\begin{array}{l}\text { Troca gasosa (respiração); } \\
\text { filtro bio lógico }\end{array}$ \\
\hline Corpo do peixe & - & - & - \\
\hline Listra; linha & Linha lateral & $\begin{array}{l}\text { "Caracteriza o peixe; diz a } \\
\text { qualidade do peixe; diferencia as } \\
\text { marca" }\end{array}$ & $\begin{array}{l}\text { Órgão com função } \\
\text { sensorial }\end{array}$ \\
\hline Escamas & Escamas & $\begin{array}{l}\text { "Peixe que tem, é peixe de } \\
\text { primeira" }\end{array}$ & $\begin{array}{l}\text { Proteção da pele contra } \\
\text { choques e parasitas }\end{array}$ \\
\hline Lombo & - & "Onde fica a carne" & - \\
\hline Barriga & - & "Ta a parte interna" & - \\
\hline $\begin{array}{l}\text { Aba; barbatana; } \\
\text { nadadeira; asa; ba rbela }\end{array}$ & Nadadeiras & $\begin{array}{l}\text { "Equilibra o corpo; governa ele; } \\
\text { controla; nada" }\end{array}$ & $\begin{array}{l}\text { Estabilizadoras; permitem } \\
\text { manobras rápidas }\end{array}$ \\
\hline Esporão & Raios & "Furar; proteção" & Constitui as nadadeiras \\
\hline Imbigo & Ânus & $\begin{array}{l}\text { "Onde ele produz; por onde eles } \\
\text { cruzam" }\end{array}$ & Liberação de excrementos \\
\hline Serrilha & - & - & - \\
\hline Rabo; cauda & $\begin{array}{l}\text { Nadadeira } \\
\text { caudal }\end{array}$ & $\begin{array}{l}\text { "Nadar; dá mais velocidade; guia } \\
\text { o peixe; leme" }\end{array}$ & $\begin{array}{l}\text { Confere impulso para a } \\
\text { natação }\end{array}$ \\
\hline Bucho (parte interna) & $\begin{array}{l}\text { Bexiga } \\
\text { natatória }\end{array}$ & “Bolsa; guarda oxigênio” & $\begin{array}{l}\text { Auxilia na flutuação; } \\
\text { captação de sons }\end{array}$ \\
\hline
\end{tabular}

* Orr (1986), Carvalho-Filho (1992) e Szpilman (2000). 
Apêndice 2. Comparação entre o conhecimento nativo (Acupe, Santo Amaro, Bahia) e o conhecimento acadêmico relativo a codificação da topografia corporal do camarão.

\begin{tabular}{|c|c|c|c|}
\hline $\begin{array}{l}\text { Nome(s) } \\
\text { vernacular(es) }\end{array}$ & $\begin{array}{l}\text { Nome na } \\
\text { literatura }\end{array}$ & $\begin{array}{l}\text { Função atribuída pelos } \\
\text { nativos }\end{array}$ & Função atribuída na literatura* \\
\hline Cabeça & Cefalotorax & - & - \\
\hline Olho & Olho & "Ver" & Visão \\
\hline Boca & Cavidade bucal & "Comer" & Triturar os alimentos \\
\hline Antena & Antênula & "Farejar" & Sensorial \\
\hline $\begin{array}{l}\text { Corpo; abdome; } \\
\text { carne }\end{array}$ & Abdome & - & - \\
\hline Rabo & Leque caudal & 一 & $\begin{array}{l}\text { Proporciona rápido deslocamento para } \\
\text { trás }\end{array}$ \\
\hline Barba; barbatana & Antena & $\begin{array}{l}\text { "Localiza os lugar a onde } \\
\text { vai; é o ouvido dele; } \\
\text { orienta; avisa do perigo; } \\
\text { enfeite; identifica o } \\
\text { alimento; ouve o som por } \\
\text { isso aí" }\end{array}$ & Sensorial e auxílio na natação \\
\hline $\begin{array}{l}\text { Esporão; espinho; } \\
\text { quilha; serrilha } \\
\text { (anterior) }\end{array}$ & Rostro & $\begin{array}{l}\text { "Equilibra ele na água; } \\
\text { defesa; proteção; fica } \\
\text { preso na red e pela } \\
\text { serrilha" }\end{array}$ & - \\
\hline $\begin{array}{l}\text { Casca; concha; } \\
\text { gomozinho; junta; } \\
\text { placa das costa }\end{array}$ & $\begin{array}{l}\text { Pleura dos somitos } \\
\text { abdominais }\end{array}$ & $\begin{array}{l}\text { "Proteger; reveste o } \\
\text { corpo; serve para a } \\
\text { locomoção deles porque } \\
\text { abre e fecha" }\end{array}$ & - \\
\hline $\begin{array}{l}\text { Esporão; espinho } \\
\text { (posterior) }\end{array}$ & Constitui o telso & "Defesa" & - \\
\hline $\begin{array}{l}\text { Cauda; rabo; } \\
\text { nadadeira; leme; } \\
\text { aba }\end{array}$ & Urópodo & $\begin{array}{l}\text { "Governa; dá impulso; } \\
\text { movimentar na água" }\end{array}$ & Constitui o leque caudal. \\
\hline Reto & - & - & - \\
\hline $\begin{array}{l}\text { Barbatana; } \\
\text { nadadeira; } \\
\text { perninha; perna }\end{array}$ & Pleópodos & $\begin{array}{l}\text { "Nadar; andar; protege os } \\
\text { ovos" }\end{array}$ & $\begin{array}{l}\text { Natação; ajuda a carregar os ovos na } \\
\text { fêmea }\end{array}$ \\
\hline Cabelinho & Cerdas & - & Sensorial \\
\hline Perna & Pereiópodo & $\begin{array}{l}\text { "Ajuda a nadar; andar; } \\
\text { pegar o alimento; comer" }\end{array}$ & Locomoção e auxílio na alimentação \\
\hline Braço & $3^{\circ}$ maxilípede & - & Limpa as brânquias \\
\hline Mão & $\begin{array}{l}\text { Artículos } \\
\text { constituintes da } \\
\text { coxa e base }\end{array}$ & "Pega o alimento" & Auxílio na alimentação \\
\hline Guerra & Brânquias & $\begin{array}{l}\text { "Respirató rio; o fôlego } \\
\text { dele sai por aî" }\end{array}$ & Efetua trocas gasosas \\
\hline Cunhão do macho & Petasma & “Acasalamento" & Aparelho copulador do macho \\
\hline
\end{tabular}

*Narchi (1973), Miller \& Harley (1996), Ruppert et al. (2005) e Brusca \& Brusca (2007). 
Apêndice 3. Comparação entre o conhecimento nativo (Acupe, Santo Amaro, Bahia) e o conhecimento acadêmico relativo a codificação da topografia corporal de siris.

\begin{tabular}{|c|c|c|c|}
\hline Nome(s) vernacular(es) & $\begin{array}{l}\text { Nome na } \\
\text { literatura }\end{array}$ & $\begin{array}{l}\text { Função atribuída pelos } \\
\text { nativos }\end{array}$ & $\begin{array}{l}\text { Função atribuída na } \\
\text { literatura* }\end{array}$ \\
\hline Casco; carapaça & Carapaça & $\begin{array}{l}\text { "Protege as partes } \\
\text { internas" }\end{array}$ & Proteção das vísceras \\
\hline $\begin{array}{l}\text { Antena; barba; barbilha; } \\
\text { barbatana; barbazinha; } \\
\text { sobrancelha; cabelo dos } \\
\text { olhos; pestana }\end{array}$ & Antenas & $\begin{array}{l}\text { "Limpa os olhos; se } \\
\text { comunica entre eles" }\end{array}$ & Sensorial \\
\hline Olho & Olho & "Ver" & Visão \\
\hline Boca & Cavidade bucal & "Comer" & Triturar os alimentos \\
\hline Peito & Esternos torácicos & "Onde fica a carne" & - \\
\hline $\begin{array}{l}\text { Esporão; ponta do casco; } \\
\text { serrilha }\end{array}$ & - & "Defesa" & Defesa \\
\hline $\begin{array}{l}\text { Imbigo; ferro; tampa; } \\
\text { tabaca; xoxota; pênis }\end{array}$ & Abdome & $\begin{array}{l}\text { "Diferencia macho de } \\
\text { fêmea" }\end{array}$ & $\begin{array}{l}\text { Recobre o órgão sexual; permite } \\
\text { diferenciar os sexos masculino e } \\
\text { feminino }\end{array}$ \\
\hline Junta & Carpo & - & - \\
\hline Pernas & Pereiópodos & "Andar" & Locomoção \\
\hline Joelho; nó; junta & Carpo & - & - \\
\hline Unha & Dátilo & "Para fixar no chão" & - \\
\hline Braço & Pereiópodos & "Segura a comida" & Porta as quelas \\
\hline Boca do braço & Quelas & $\begin{array}{l}\text { "Segura a comida; se } \\
\text { defende com isso }\end{array}$ & Serve para cortar os alimentos \\
\hline Leme; asa & Pernas natatórias & $\begin{array}{l}\text { "Cont rola o corpo dele; } \\
\text { guia do siri; nadar" }\end{array}$ & Atua como remo \\
\hline
\end{tabular}

*Narchi (1973), Miller \& Harley (1996), Ruppert et al. (2005) e Brusca \& Brusca (2007).

Apêndice 4. Comparação entre o conhecimento nativo (Acupe, Santo Amaro, Bahia) e o conhecimento acadêmico relativo a codificação da topografia corporal do caranguejo.

\begin{tabular}{|c|c|c|c|}
\hline $\begin{array}{l}\text { Nome(s) } \\
\text { vernacular(es) }\end{array}$ & Nome na literatura & $\begin{array}{l}\text { Função atribuída } \\
\text { pelos nativos }\end{array}$ & Função atribuída na literatura* \\
\hline Casco & Carapaça & "Protege o corpo" & Proteção \\
\hline Olho & Olho composto & "Ver" & Visão \\
\hline Boca & Cavidade bucal & "Comer; se alimentar" & Tritura $\mathrm{r}$ os alimentos \\
\hline Peito; barriga & Esternos torácicos & - & Aloja o abdome \\
\hline Boca das perna & Quelas & "Pegar a comida" & Defesa e auxilia na alimentação \\
\hline Perna & Pereiópodos & $\begin{array}{l}\text { "Locomover; andar; } \\
\text { cavar" }\end{array}$ & Locomoção \\
\hline Gomo & Carpo & - & Articulação \\
\hline Unha & Dátilo & "Não escorregar" & - \\
\hline Junta & Base & - & - \\
\hline Cabelo & Pelos & $\begin{array}{l}\text { "Os machos têm } \\
\text { cabelo nas pernas, as } \\
\text { fêmeas não!" }\end{array}$ & - \\
\hline Tampa; imbigo; pênis & Abdome & $\begin{array}{l}\text { "Reproduzir; produzir } \\
\text { os filhote; guardar o } \\
\text { pinto" }\end{array}$ & Abrigo e transporte dos ovos \\
\hline
\end{tabular}

